\title{
ESCRITA ORTOGRÁFICA E REVISÃO DE TEXTO EM BRAILLE: UMA HISTÓRIA DE RECONSTRUÇÃO DE PARADIGMAS SOBRE O APRENDER
}

\author{
Clarissa de Arruda Nicolaiewsky ${ }^{*}$ \\ JANE CORREA**
}

RESUMO: O desenvolvimento da escrita ortográfica pela criança é uma ferramenta importante para a expressão e organização do seu pensamento através do texto escrito. A revisão textual contribui de forma significativa neste desenvolvimento ao possibilitar que a criança reflita sobre as escolhas lingüísticas que realiza ao escrever. No entanto, se o aprendiz percebe o erro como evidência de seu fracasso em aprender, a revisão da própria produção pode ser uma experiência dolorosa. Este trabalho descreve o processo de revisão de texto realizado por uma criança cega, explorando a importância da realização de atividades de natureza metalingüística e do fazer-de-conta para o domínio da escrita ortográfica no sistema Braille, desenvolvimento da auto-estima e reconstrução de paradigmas sobre o aprender.

Palavras-chave: Escrita ortográfica. Revisão de texto. Braille.

ORTHOGRAPHIC WRITING AND TEXT REVISION IN BRAILLE:

A STORY ABOUT RECONSTRUCTING LEARNING PARADIGMS

ABSTRACT: The development of the orthographic writing is a tool for children to express and organize their thought through their written production. Text revision contributes to this development as it allows children to think about the linguistic choices they make in their writing. However, if children take their mistakes as proof of their failure to learn, the revision of their own written production

* Mestre em Psicologia pela Universidade Federal do Rio de Janeiro (UFRJ).

E-mail: clarissanicolaiwskey@yahoo.com.br

** Doutora em Psicologia e docente do Instituto de Psicologia da UfRJ.

E-mail: correa@psicologia.ufrj.br

Cad. Cedes, Campinas, vol. 28, n. 75, p. 229-244, maio/ago. 2008 
may be seen as a painful experience. This study describes the process of text revision carried out by a blind child, pinpointing the importance of metalinguistic activities and of the use of role-play to the acquisition of writing in Braille, to the development of self-esteem and to the reconstruction of learning paradigms.

Key words: Orthographic writing. Text revision. Braille.

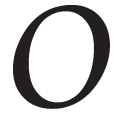

domínio das convenções ortográficas tem papel importante no aprimoramento das habilidades textuais da criança, uma vez que o emprego de tais convenções facilita a comunicação escrita entre os usuários de uma determinada língua (Morais, 2000). As normas ortográficas auxiliam a inteligibilidade do texto, possibilitando desta forma a comunicação através da escrita. $\mathrm{O}$ ato de ler não é possível sem que ocorram concomitantemente os processos de decodificação e compreensão do texto escrito. Neste sentido, o domínio do sistema de escrita é imprescindível tanto para o entendimento do texto lido como para a clareza do texto escrito.

A aquisição da escrita ortográfica não é resultado direto da exposição da criança ao material impresso, mas do aprendizado significativo da natureza e organização do sistema de escrita pela criança. Assim, a reflexão acerca das palavras e de sua grafia é fundamental para o desenvolvimento da escrita ortográfica como uma ferramenta para a expressão e organização do pensamento através do texto escrito. A revisão de textos pode contribuir de forma significativa neste desenvolvimento ao possibilitar que o aprendiz reflita sobre as escolhas lingüísticas que realiza ao escrever. Descrevemos neste trabalho o processo de revisão de texto realizado por uma criança cega, explorando a importância da realização de atividades de natureza metalingüística e do fazer-de-conta para o domínio da escrita ortográfica no sistema Braille, desenvolvimento da autoestima e reconstrução de paradigmas sobre o aprender.

\section{Habilidades metalingüísticas e escrita ortográfica}

O desenvolvimento de competências metalingüísticas é essencial ao processo de aquisição de uma ortografia alfabética. São essas habilidades que possibilitam a construção da escrita e seu manuseio de forma reflexiva e funcional. Segundo Gombert (1992), a metalinguagem 
está inserida no campo da metacognição, diferenciando-se das outras habilidades deste construto por não ser seu objeto de estudo uma função cognitiva, como exemplo a metamemória, mas a própria linguagem. A metalinguagem se refere, portanto, à reflexão sobre a linguagem e à manipulação intencional de seus componentes (Correa, 2004).

Mesmo para escritores experientes, a primeira versão de um texto raramente é satisfatória (Garcez, 2002). Parte fundamental do processo de escrita é fazer releituras e reescritas. Na revisão textual é possível ao autor rever a organização das idéias e as escolhas lingüísticas que realizou. No entanto, a revisão de textos não é algo espontâneo, principalmente para a criança, porque requer que tomemos o texto como objeto de nossas operações cognitivas. $\mathrm{O}$ trabalho de revisão de um texto assume, portanto, um caráter metalingüístico à medida que se fundamenta em uma reflexão sobre a estrutura do texto tanto no que se refere à sua coerência como à sua composição escrita. No processo de revisão de texto somos, então, confrontados com a propriedade e adequação de nossas escolhas, e desta forma com nossos erros. Neste sentido, os erros são meios através dos quais podemos avançar em nosso conhecimento, reorganizando nossos esquemas cognitivos. Segundo Swenson (1991), para que uma criança cega mergulhe no processo de letramento e desenvolva uma escrita funcional e reflexiva é importante que ela passe pelo mesmo processo de produção textual que os adultos, realizando rascunhos e diversas revisões de seu texto até sua versão final.

\section{O processo de revisão de texto em Braille}

As letras em Braille são formadas a partir da combinação de seis pontos que compõem o que é chamado de cela Braille. A cela é formada por duas colunas e três linhas de pontos. A localização dos pontos é dada de cima para baixo, primeiramente na coluna da esquerda e posteriormente na coluna da direita e são denominados respectivamente pontos números $1,2,3,4,5$ e 6 . Cada combinação de pontos em relevo forma, portanto, determinada letra ou sinal de pontuação. A letra c, por exemplo, é formada pelos pontos 1 e 4, como mostra a Figura 1 a seguir.

Por serem formadas a partir da combinação de seis pontos, as letras em Braille são bem mais semelhantes entre si do que as letras do sistema impresso, o que torna o sistema Braille mais difícil de ser 
aprendido (Pring, 1994). Como os pontos devem ficar em relevo, a escrita na reglete é realizada da direita para a esquerda, para que quando a folha seja virada as letras estejam em relevo, sendo lidas então da esquerda para a direita. Quando a criança encontra-se em processo de aquisição da língua escrita através do sistema Braille ela comete muitos erros nos pontos, seja por haver confundido a seqüência de pontos de determinada letra, seja por ter escorregado o punção na hora de escrever. Sendo assim, além da existência de erros relacionados à escrita da língua portuguesa, há também erros de outra ordem, relativos ao domínio do próprio sistema.

\section{Figura 1}

Cela Braille

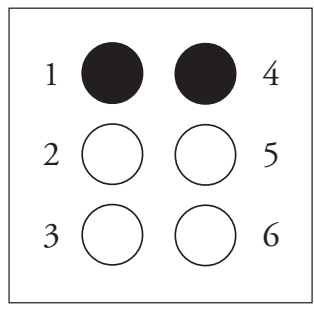

Como a escrita das letras em Braille é padronizada, os instrumentos utilizados possuem especificidades que dificultam a correção de erros. Não é possível inserir nenhuma letra a mais no meio de uma frase, como fazemos tranqüilamente na escrita em tinta, quando, por exemplo, apagamos a palavra incorreta e a reescrevemos em um tamanho reduzido. O oposto também não é possível, já que ao apagarmos uma letra excedente em Braille sobra um espaço em branco no meio da palavra. Além disso, caso queiramos trocar uma palavra por outra, mesmo que esta tenha o mesmo número de letras, será necessário apagar a palavra indesejada de forma impecável para que a escrita por cima dela fique legível. Além do mais, o desejo de escrever algo por cima ou de inserir um ponto antes omitido em uma letra demanda do escritor o conhecimento da linha do texto e da frase em que se está o erro, para que, ao recolocar o papel na reglete, o escritor possa encontrar o erro, já que o 
papel fica virado ao avesso no ato da escrita. A técnica de revisão em Braille é, portanto, bastante complexa. No caso do sistema Braille, onde há dificuldade, especialmente para as crianças, em apagar palavras e frases e reescrever por cima de forma legível, a revisão terá inicialmente sua maior ênfase nas formas gráficas, ou seja, nos aspectos ortográficos da língua.

\section{Aprendizagem e subjetividade}

O conceito que fazemos de nós mesmos é um processo complexo que se dá ao longo de nossas vidas relacionado à cultura em que vivemos e às interaçôes sociais que estabelecemos em nossa experiência cotidiana (Durkin, 1995). A capacidade de tomarmos consciência de quem somos, de nossos sentimentos, características e potenciais é constituída no contexto das relações que estabelecemos ao longo de nosso desenvolvimento em um processo de apropriação e construção conjunta de significações acerca de nós mesmos e do mundo em que vivemos (Salgado, Pereira \& Jobim e Souza, 2005). A avaliação que a criança faz sobre si mesma nos diferentes contextos em que atua contribui de forma diferenciada para o desenvolvimento de sua auto-estima. De modo geral, o conceito que a criança faz de si mesma tende a se correlacionar com seu desempenho nos contextos de sua experiência que mais valoriza.

$\mathrm{O}$ impacto exercido pela escola na vida da criança vai além daquele semelhante ao seu desenvolvimento intelectual. Nas relações estabelecidas com seus professores e pares quando da participação em atividades conjuntas na escola, a criança pode construir/reconstruir uma representação para si própria e para suas ações (Cole \& Cole, 2004). As concepçôes que as crianças possuem acerca de suas competências como aprendizes relacionam-se à maneira como compreendem suas dificuldades de aprendizagem e as de seus colegas, como também ao entendimento das diversas formas e recursos que possuem para superá-las. Correa e MacLean (1999) analisaram as narrativas de crianças ao final da classe de alfabetização acerca do aprender a ler e a escrever. As crianças que foram bemsucedidas na classe de alfabetização produziram um número significativo de histórias relatando o sucesso de um personagem que, como elas, aprendeu a ler e a escrever e tornou-se motivo de alegria e orgulho para pais e professores. Por outro lado, a maioria das crianças que encontraram dificuldade durante o processo de alfabetização simplesmente descreveu a 
Escrita ortográfica e revisão de texto em Braille...

rotina escolar ou o tipo de atividade realizada pelo protagonista da história como forma de evitar expressar através dele sua própria experiência de aprendizagem ou de demonstrar seu aprisionamento a uma seqüência de atividades inexpressivas para ela. O sucesso no aprendizado foi percebido pelas crianças como promovendo suas capacidades intelectuais. As histórias que narraram o insucesso do personagem em aprender a ler e a escrever sugerem que as crianças perceberam o insucesso como relacionado às suas características. De forma geral, a criança não aprende porque é preguiçosa ou incapaz, não tendo se esforçado o suficiente para aprender, tornando-se, como conseqüência, pouco inteligente.

As vivências escolares têm papel fundamental para a constituição do sujeito, seus valores, atitudes, sua forma de ver o mundo e a si mesmo. Os anos escolares iniciais formarão a base das relações que a criança terá com a escola e com o seu próprio processo de aprendizagem. Tais conceitos afetam, conseqüentemente, a forma como as crianças irão lidar com suas experiências seguintes (Pajares \& Schunk, 2001). Neste sentido, a aprendizagem torna-se significativa para o sujeito quando as experiências, ao invés de limitar o seu desenvolvimento, sua curiosidade e crença em si mesmo, os expandem. Para isso, é importante levarmos em conta as capacidades cognitivas dos aprendizes bem como seus interesses, sentimentos e valores (Mogilka, 2003).

A aprendizagem ocorre de forma efetiva quando há uma implicação do aprendiz em sua relação com o objeto de conhecimento. É necessário, portanto, um sujeito ativo na construção de seu próprio conhecimento, já que a finalidade última de cada intervenção pedagógica deve ser contribuir para que o aprendiz desenvolva a capacidade de realizar aprendizagens significativas por si mesmo (Coll, 1994).

A aquisição da língua escrita é uma importante conquista para a criança, pois representa sua iniciação efetiva no processo de escolarização. O domínio da escrita é fundamental para que a criança seja bem-sucedida em sua trajetória escolar já que todo saber formal veiculado na escola é realizado, primordialmente, por meio da leitura e da escrita. É nesta importante fase que o aprendiz se depara de forma mais intensa com a presença de erros em suas produções.

Em realidade, o erro está presente em qualquer processo de aprendizagem, dentro ou fora da escola. Contudo, o erro não é comumente visto como parte integrante e imprescindível do processo de aprendizagem. Ao 
contrário, é tomado tanto como evidência da incapacidade da criança, quanto como empecilho ao próprio aprender. De acordo com esta perspectiva, a presença do erro é tida como pedagogicamente indesejável, devendo ser, portanto, evitado. Por sua vez, os aprendizes, a cada vez que se deparam com seus erros, os tomam como sinal de seu fracasso em aprender. Sendo assim, há que se evitar olhá-lo ou expô-lo. Ao contrário, sendo o erro inerente ao aprender, sua ocorrência deveria deflagrar um processo de tomada de consciência que envolveria olhar para esse erro, refletir sobre ele e aprender com ele. Assim, o erro deveria ser tomado em seu sentido construtivo, tornando-se algo sobre o qual devemos pensar e não evitar.

\section{Aprendizagem e desenvolvimento da criança cega}

A ação autônoma e o reconhecimento de sua competência são importantes para o desenvolvimento da criança cega. Conforme argumentam Cobo, Rodríguez e Bueno (2003), raramente, em seu cotidiano, a criança cega tem a oportunidade de presenciar uma pessoa visonormal errando. Entretanto, as pessoas não costumam dizer o quanto, quando e como erram às crianças cegas. Assim, é possível para a criança cega imaginar que os visonormais raramente erram. Como conseqüência, a criança cega pode tornar-se bastante exigente para consigo própria e, então, intolerante com seus próprios erros (Cobo, Rodríguez \& Bueno, 2003).

A criança cega em processo de aquisição da língua escrita utilizando o sistema Braille se depara com uma dupla dificuldade. O aprendiz deficiente visual é lembrado no dia-a-dia pelo que não pode, pelos seus limites, o que por si só já traz conseqüências para o desenvolvimento de sua auto-estima, dependendo da forma como os adultos em seu contexto social lidam com suas diferenças. Soma-se a isto, na situação escolar, os obstáculos encontrados no aprendizado da língua escrita pelo sistema Braille, um código de escrita tátil que, por suas peculiaridades, torna-se mais complexo do que o sistema impresso. Desta forma, o sistema Braille por suas características incita uma maior propensão a erros, além da dificuldade que é para o aprendiz apagar os erros de sua produção escrita. Assim, a criança cega que encontra dificuldades neste aprendizado experimenta uma dupla exclusão. É fundamental, portanto, que a criança cega estabeleça uma relação positiva com o erro para que sua ocorrência não afete o conceito que faz de si mesma como aprendiz. 
Escrita ortográfica e revisão de texto em Braille...

Revisão de texto e reescrita de paradigmas sobre o aprender

Tatiana (nome fictício) tinha 11 anos ao iniciar sua participação nas Oficinas de Leitura e Escrita, projeto de pesquisa-intervenção realizado com auxílio da FAPERJ e do CNPq. Tatiana estudava em uma classe especial de uma escola municipal do Rio de Janeiro há quatro anos e, no ano seguinte, iria para uma classe regular na mesma escola. Ela apresentava dificuldade em compreensão de textos e no domínio da escrita ortográfica, o que comprometia muito o entendimento de seu texto. A partir das observaçôes realizadas acerca do desenvolvimento de Tatiana em leitura e escrita, foram iniciadas atividades de compreensão de histórias, para que, posteriormente, em função do seu progresso em leitura, fosse enfatizado o desenvolvimento do conhecimento ortográfico por meio da produção de texto (Nicolaiewsky, 2004). Dadas as dificuldades de Tatiana com o domínio do sistema de escrita, foram iniciadas atividades de revisão de texto como forma de desenvolver a sua escrita em busca de uma maneira de agir mais reflexiva com relação à própria escrita. Uma vez que Tatiana não dominava como fazer as correçôes em Braille, foram seguidas as orientaçôes de Swenson (1991) e sugerido a Tatiana que marcasse os diferentes erros com diferentes adesivos para sua referência, redigindo as palavras modificadas em outra folha, que seria, então, anexada ao texto como uma forma de errata. Tatiana se mostrou bastante apreensiva com esta proposta, ficando descontente com a quantidade de adesivos colocados em seu texto, afirmando que havia "errado tudo", pedindo para não mais utilizarmos os adesivos. Esta não foi a primeira vez que Tatiana expressava sua intolerância e frustração com os próprios erros. Era comum a Tatiana, ao ler sua produção escrita, parar em determinados erros, dando a clara impressão de que havia percebido que algo estava errado, e mesmo assim seguir adiante como se nada tivesse acontecido.

A revisão de texto é uma tarefa metalingüística para a qual o debruçar sobre o próprio erro é fundamental. No entanto, esta não era uma atividade possível a Tatiana em função do que o erro representava para ela. Tatiana percebia o erro como uma comprovação de seu fracasso. Desta maneira, lidar com seus próprios erros era para ela doloroso e insuportável. Deparamo-nos, assim, com um impasse: Tatiana não conseguiria continuar o seu processo de aprendizado se não entrasse em contato com seus próprios erros, e entrar em contato com seus erros significava para a menina uma experiência frustrante. 
Como Tatiana apresentava bastante dificuldade em fazer a revisão de seu texto devido à ansiedade que sentia em relação aos próprios erros, lançamos mão de uma adaptação da técnica de inversão de papéis, freqüentemente utilizada na clínica da Gestalt-terapia. Esta técnica consiste em propor que o indivíduo se coloque no lugar de outra pessoa, de forma a propiciar uma maior conscientização de seus sentimentos e pensamentos e, a partir de um novo olhar, ser possível agir e explorar diversas alternativas de forma segura, já que o indivíduo se encontra em uma relação acolhedora (Polster \& Polster, 2001). Assim, Tatiana precisaria experimentar estar em outro papel, daquele que ensina, o que lhe permitiria lidar com o erro com uma implicação afetiva menor. A partir de uma nova perspectiva, Tatiana estaria experimentando novas formas de se relacionar com o erro. Foi proposto a Tatiana, então, ajudar uma criança imaginária com a revisão de seu texto. As dificuldades de escrita desta criança imaginária eram bem similares as de Tatiana. Desta forma, Tatiana não precisaria entrar em contato com os próprios erros, mas com os erros de um outro, o Rodrigão, como ela espontaneamente o nomeou. Lançando mão desta atividade, propiciamos também que, neste momento, Tatiana projetasse no outro, o Rodrigão, aquilo que ela não conseguia aceitar em si mesma: seus sentimentos relacionados ao fracasso. Assim sendo, Tatiana poderia, com maior facilidade, entrar em contato com os erros, já que seria mais fácil lidar com aquilo que lhe incomoda quando isto é apontado no outro.

Em um primeiro momento foi realizado o jogo dos erros onde, em diversos pares de frases, Tatiana, por comparação à frase-alvo, deveria marcar o erro na frase escrita pelo Rodrigão, explicando a razão de sua marcação. Neste tipo de atividade, na qual existe a possibilidade de comparação, a frase correta serve de apoio, o que facilita a descoberta do erro. Nosso papel foi o de estimular em Tatiana seu interesse e curiosidade, ajudando-a sem, no entanto, fornecer-lhe diretamente a resposta. Esta atitude de respeito do facilitador pelo tempo do aprendiz é fundamental para que o aprendizado aconteça de forma significativa. Assim como na prática psicoterápica é um desserviço ao cliente fazer algo por ele, retirando-lhe assim sua responsabilidade e privando-o da experiência de aprendizagem e do estímulo resultante de fazer algo por si próprio (Fagan \& Sheperd, 1980), estes mesmos princípios podem ser aplicados às situações didáticas e atividades psicopedagógicas em geral. Dessa forma, propiciar uma reintegração de sua atenção e conscientização no que 
Escrita ortográfica e revisão de texto em Braille...

está fazendo permite que a criança possa encontrar suas próprias soluções através de suas dificuldades (Fagan \& Shepherd, 1980).

Em um segundo momento, foram trazidas frases do Rodrigão para revisão. Cada frase continha apenas um erro que devia ser encontrado e corrigido. A produção de apenas um erro por frase, nesta etapa, tornava a tarefa mais fácil, à medida que Tatiana já não contava com o apoio de uma frase-modelo. Este tipo de atividade foi interessante porque neste caso o objetivo do jogo era o de encontrar algo que durante toda sua trajetória escolar Tatiana se esforçou por esconder. Encontrar os erros na produção do Rodrigão, refletir sobre eles e corrigi-los possibilitou a Tatiana vislumbrar outra maneira de se lidar com o erro.

As correções nas produções escritas eram feitas de duas formas: Tatiana reescrevia a palavra corretamente em uma etiqueta e a colávamos por cima (após apagar os pontos da palavra errada), ou reescrevia a frase na etiqueta caso a palavra corrigida não coubesse no meio da frase. Optamos por propor as correções desta forma porque, como explicado anteriormente, o aprendiz iniciante em Braille geralmente encontra uma dificuldade dupla: a) apagar os pontos de forma que a reescrita fique legível e b) achar o local certo na frase para realizar a correção já que o papel fica virado ao contrário na hora de escrever. Tatiana realizou tais atividades com interesse e entusiasmo. A diferença em sua forma de lidar com o erro do outro foi tão significativa que ela pediu para que fosse levada "mais revisão" nos próximos encontros, "para ficar craque", o que foi feito por mais algumas vezes, intercalando-se as atividades de revisão e a leitura de histórias.

Foi proposto, posteriormente, que Tatiana escrevesse "como o Rodrigão", ou seja, que fizesse erros propositadamente em sua escrita. Esta atividade é também conhecida como tarefa de erro intencional. A habilidade de errar intencionalmente revela o conhecimento que o aprendiz já tenha construído sobre as convenções da escrita (Morais, 2000; Meireles \& Correa, 2006). Nosso objetivo, neste caso, não foi só o de examinar o conhecimento de Tatiana, mas, principalmente, o de propiciar que o erro fizesse parte da escrita de forma essencialmente lúdica, já que errar não era apenas permitido, mas demandado. Assim sendo, na tarefa de erro intencional, o aprendiz recebe a "permissão" de errar, já que errar faz parte da própria atividade. A tarefa de erro intencional é, portanto, uma atividade de natureza metalingüística, em que a criança 
tem a oportunidade de refletir sobre as diversas possibilidades de transgressões na escrita. Esta foi uma experiência tão importante que Tatiana fez questão de fazer o maior número de transgressões possíveis, sentindo grande satisfação durante a realização da tarefa.

Lançamos mão, também, da atividade em que Tatiana era a professora, trazendo para correção frases que havia escrito na tarefa de erro intencional. Dessa forma, Tatiana teria a chance de explicar suas próprias transgressões. Tatiana se interessou bastante pela atividade. Ela ia lendo cada frase, dizendo o que estava errado para que a facilitadora, que fazia o papel do Rodrigão, reescrevesse as frases. Durante a realização da atividade, Tatiana ia dizendo à facilitadora frases como: "Vai escrever tudo certinho, você é inteligente", "Se escrever empastelado (sem espaços entre palavras) não dá pra entender" e "Muito rápido você erra, escrita é hora séria”.

De fato, o caráter lúdico de uma atividade permite que a criança experimente outras formas de solucionar problemas (Kishimoto, 1998; Vygotsky, 1994). Além disso, brincar de fazer-de-conta possibilita que a criança explore o seu mundo, aprenda sobre ele e elabore seus sentimentos acerca do mesmo, além de experimentar novas formas de ser (Oaklander, 1980). De fato, a inserção do fazer-de-conta nas atividades psicopedagógicas supracitadas permitiu que Tatiana experimentasse o contato com o erro de uma nova forma, reconfigurando seus sentimentos e idéias sobre ele.

A promoção de um contexto onde a criança possa fazer escolhas e se mostrar de forma mais plena possibilita um desenvolvimento emocional e cognitivo mais integrado. Dessa forma, as brincadeiras contribuem para o desenvolvimento de recursos cognitivos e afetivos (Pedroza, 2005; Zanella \& Andrada, 2002). Em um contexto lúdico, os aprendizes passam a demonstrar mais interesse e curiosidade, expressando seu saber e deparando-se, também, com o seu não-saber como condição possível, e não como um obstáculo, para o conhecimento.

A atitude de respeito do facilitador em relação à criança em aprendizagem, com aceitação plena de suas características e crença em suas potencialidades, fundamenta-se nos preceitos da relação dialógica (Aguiar, 2005; Hycner, 1995). Tal forma de agir é importante para o estabelecimento de uma relação construtiva, na qual, a partir do momento em que a criança se sente amada e respeitada, a criança também 
é capaz de se aceitar, podendo estar mais atenta à forma como se relaciona com o mundo. Somente por meio desse tipo de relação, onde há uma aceitação genuína, é possível estabelecer um processo de aprendizagem realmente significativo (Elias, 2000; Rogers, 1961), já que, através da relação estabelecida entre o aprendiz e o educador, a criança se perceberá como sujeito ativo em seu próprio processo de aprendizado. Tatiana, por exemplo, demonstrou cada vez mais curiosidade e vontade de aprender, pedindo que fossem levados diferentes gêneros de textos além de histórias para as Oficinas de Leitura e Escrita: letras de música, uma biografia de Louis Braille e mesmo frases com mentiras para marcar o dia $1^{\circ}$ de abril, Dia da Mentira.

A partir desta mudança de paradigma em relação ao erro, foi possível a Tatiana realizar, de forma mais sistemática, a revisão de seus próprios textos, sem a ansiedade presenciada anteriormente. As atividades acima descritas permitiram que Tatiana se tornasse mais atenta às suas dificuldades, não apenas durante a revisão de seus textos, mas também durante a escrita inicial dos mesmos. Aos poucos, o uso de etiquetas foi descontinuado em favor das formas convencionais de correção da grafia em Braille. Para isso, foi preciso levar Tatiana ao entendimento de quando era necessário retirar ou adicionar determinado ponto para alcançar a grafia convencional de determinada palavra ou expressão. A prática dessas técnicas de revisão é fundamental para uma melhor compreensão do sistema Braille. Tatiana foi, aos poucos, compreendendo a lógica desse tipo de correção e, ao final do ano letivo, já era capaz de perceber com facilidade quais pontos estavam faltando e quais estavam em excesso na sua produção prejudicando a inteligibilidade de seu texto escrito.

\section{Considerações finais}

Os resultados observados na produção de Tatiana foram extremamente significativos. Pôde-se perceber que suas habilidades na leitura e escrita utilizando o sistema Braille se desenvolveram visivelmente. Tatiana passou a apresentar uma atitude mais reflexiva na revisão de sua produção escrita, escolhendo a melhor forma de correção para cada caso e realizando-a com grande autonomia. Mais ainda, compreendeu que um dos maiores objetivos da escrita é a comunicação, podendo, a partir de então, tomar para si o ato de escrever, realizando-o de forma mais responsável, consciente e atenta a partir do domínio de suas escolhas lingüísticas. Esta 
mudança significativa na relação que ela estabeleceu com sua produção escrita possibilitou uma transformação na compreensão que tinha de seu próprio aprendizado, instigando seu interesse em aprender mais. Tais mudanças, como a própria reconceitualização do erro, acarretaram, conseqüentemente, em uma melhora significativa em sua auto-estima. Tatiana passou a acreditar em suas potencialidades e a se perceber como alguém capaz de aprender cada vez mais. A ida à classe regular, que anteriormente era imaginada com grande grau de ansiedade, pôde ser experimentada de forma mais tranqüila e confiante, ao afirmar que estava "indo muito bem" e que "iria passar de ano".

O percurso realizado por Tatiana nas Oficinas de Leitura e Escrita guarda em si vários ensinamentos quer sobre o domínio do sistema de escrita como fundamento das práticas de letramento de crianças cegas, quer da intrincada relação entre aprendizagem e construção da subjetividade. Atividades de caráter metalingüístico aliadas ao fazer-de-conta auxiliam o domínio das convenções do sistema de escrita como instrumento para o desenvolvimento da habilidade de produção textual através do desenvolvimento de uma atitude mais implicada e reflexiva com a própria escrita. A realização de tais atividades em um contexto dialógico permite o entendimento das dificuldades encontradas como possibilidades de reconstrução e aprimoramento do conhecimento. Finalmente, a relação que a criança cega estabelece com seu processo de aprendizagem exerce enorme influência no desenvolvimento de sua auto-estima e na constituição de si mesma como sujeito de seu aprender. As situações de aprendizagem organizadas para a criança cega funcionam, dessa forma, como contextos de interação a partir dos quais a criança escreve, revisa e reescreve sua história de aprendizagem.

Recebido em março de 2008 e aprovado em julho de 2008.

\section{Referências}

AGUIAR, L. Gestalt-terapia com crianças: teoria e prática. São Paulo: Livro pleno, 2005.

COBO, A.D.; RODRÍGUEZ, M.G.; BUENO, S.T. Personalidade e auto-imagem do cego. In: MarTín, M.B.; Bueno, S.T. Deficiência visual: 
Escrita ortográfica e revisão de texto em Braille...

aspectos psicoevolutivos e educativos. São Paulo: Livraria Editora Santos, 2003. p. 117-128.

COLE, M.; COLE, S.R. O desenvolvimento da criança e do adolescente. Porto Alegre: Artes Médicas, 2004.

COLL, C.A. construção do conhecimento no âmbito das relações interpessoais e suas implicações para o currículo escolar. In: Coll, C. Aprendizagem escolar e construção do conhecimento. Porto Alegre: Artes Médicas, 1994.

CORREA, J. A avaliação da consciência sintática na criança: uma análise metodológica. Psicologia: Teoria \& Pesquisa, Brasília, DF, v. 20, n. 1, p. 69-75, 2004.

CORREA, J.; MACLEAN, M. Aprendendo a ler e a escrever: a narrativa das crianças sobre a alfabetização. Psicologia: Reflexão \& Crítica, Porto Alegre, v. 12, n. 2, 1999.

DURKIN, K. Developmental social psychology. Oxford: Blackwell, 1995.

ELIAS, G.P. A relação dialógica no processo de aprendizagem. Revista do VI Encontro Goiano da Abordagem Gestáltica, Goiânia, p. 43-49, 2000 .

FAGAN, J.; SHEPHERD, I.L. Gestalt-terapia: teoria, técnicas e aplicações. Rio de Janeiro: Zahar, 1980.

GARCEZ, L. Técnica de redação: o que é preciso saber para bem escrever. São Paulo: Martins Fontes, 2002.

GOMBERT, J. E. Metalinguistic development. Great Britain: BPCC Wheatons, 1992.

HYCNER, R. De pessoa a pessoa. São Paulo: Summus, 1995.

KISHIMOTO, T.M. Bruner e a brincadeira. In: Kishimoto, T.M. (Org.). O brincar e suas teorias. São Paulo: Pioneira, 1998.

MOGILKA, M. O que é educação democrática? Contribuições para uma questão sempre atual. Curitiba: Editora da UFPR, 2003.

MEIRELES, E.S.; CORREA, J. A relação da tarefa de erro intencional com o desempenho ortográfico da criança considerados os aspectos 
morfossintáticos e contextuais da língua portuguesa. Estudos de Psicologia, Campinas, v. 11, n. 1, p. 35-43, 2006.

MORAIS, A.G. "Por que gozado não se escreve com u no final?" - os conhecimentos explícitos verbais da criança sobre a ortografia. In: MoRAIS, A.G. (Org.). O aprendizado da ortografia. Belo Horizonte: Autêntica, 2000.

NICOLAIEWSKY, C.A. O desenvolvimento de competências metalingüisticas e o aprendizado da escrita através do sistema Braille. 2004. Monografia - Instituto de Psicologia, Universidade Federal do Rio de Janeiro, Rio de Janeiro.

OAKLANDER, V. Descobrindo crianças: a abordagem gestáltica com crianças e adolescentes. São Paulo: Summus, 1980.

PAJARES, F.; SCHUNK, D.H. Self-beliefs and school success: selfefficacy, self-concept, and school achievement. In: RIDING, R.; RAYNER, S. (Ed.). Perception. London: Ablex Publishing, 2001. p. 239-266.

PEDROZA, R.L. Aprendizagem e subjetividade: uma construção a partir do brincar. Revista do Departamento de Psicologia da UFF, Niterói, v. 17, n. 2, p. 61-76, jul./dez. 2005.

POLSTER, E.; POLSTER, M. Gestalt-terapia integrada. São Paulo: Summus, 2001.

PRING, L. Touch and go: learning to read Braille. Reading Research Quarterly, v. 29, p. 67-74, 1994.

ROGERS, C. Tornar-se pessoa. São Paulo: Martins Fontes, 1961.

SALGADO, R.G.; PEREIRA, R.M.; JOBIM E SOUZA, S. Pela tela, pela janela: questões teóricas e práticas sobre infância e televisão. Cadernos Cedes, Campinas, v. 25, n. 65, p. 9-24, 2005.

SWENSON, A. A process approach to teaching Braille writing at the primary level. Journal of Visual Impairment and Blindness, v. 85, p. 217 221, 1991.

VYGOTSKY, L.S. O papel do brinquedo no desenvolvimento. In: Vygotsky, L.S. A formação social da mente. São Paulo: Martins Fontes, 1994. 
Escrita ortográfica e revisão de texto em Braille...

ZANELlA, A.V.; ANDRADA, E.G.C. Processos de significação no brincar: problematizando a constituição do sujeito. Psicologia em Estudo, Maringá, v. 7, n. 2, p. 127-133, 2002. 